\title{
Supply and demand: estimating the real need for care while meeting the 48 hour waiting time target in a genitourinary medicine clinic by a closed appointment system
}

\author{
J Clarke, H Christodoulides, Y Taylor
}

Sex Transm Infect 2006;82:45-48. doi: 10.1136/sti.2005.018358

\begin{abstract}
Aim: To attempt to assess demand for access to sexual health services in a community where a "closed" appointment system operates in the local genitourinary medicine (GUM) clinic.

Setting: A large GUM clinic serving a provincial city in England. Appointments for new episodes are available only 1 or 2 days ahead. Service user complaints about repeated difficulty in getting through to book a visit prompted a review of all methods of access.

Methods: A prospective review of all calls received in the departmental telephone booking service was performed. Temporary extra staff manned a cascade sequence of telephone lines and recorded all calls and caller characteristics such as age and declaration of symptoms. All attempts to book an appointment in person, by written referral, or by telephone in a period of 5 working days were also logged. This total demand was compared with the actual capacity and maximum theoretical capacity of the clinic during the same time period.

Results: 626 appointments would be required in the working week to accommodate all patients within 48 hours of requesting to be seen. $84 \%$ of all calls requested a new appointment, and $77 \%$ all new appointment requests were by phone. There were 181 new appointments available; $72 \%$ of those requesting an appointment could not be seen. The clinic was working at 103\% capacity. To accommodate demand at this quiet time of the academic year, the GUM service would need to increase capacity by 3-4fold.

Conclusions: Closed appointment systems in GUM services may produce an apparent "improvement" in waiting times to 48 hours, but many callers are not able to book an appointment at all. Demand for GUM

services outstrips capacity to an extent that internal efficiency savings cannot hope to address.
\end{abstract}

Accepted for publication

21 October 2005

$\mathrm{T}$ he capacity of the network of free and open access genitourinary medicine (GUM) clinics in the United Kingdom has been acknowledged to be well below the demand from the public to use them. ${ }^{1}$ There have been a number of studies evaluating the current level of service provision and methods of access ${ }^{2}$ and proposals of service models to maximise provision within existing resources ${ }^{3}$ Waiting times for new patients have been seen to grow to unacceptable lengths. ${ }^{4}$ One method to control workload is the closed appointment system where patients must ring or present 48 hours ahead of a clinic to secure an appointment.

The GUM clinic in Leeds saw 24923 patient attendances in 2004-5, with a new to return ratio of 1:1.03, which included the $30 \%$ of all medical appointments dedicated to our cohort of 439 HIV patients. Walk-in clinics had been abandoned because of low staff morale caused by continuous severe pressure on reception staff from patients turned away from full sessions. Text (SMS) messaging for results was popular with patients and released senior nurses to develop nurse led asymptomatic screening services. Despite this and other attempts at modernisation, by June 2004 we had waiting lists extending to 12 weeks for female and 8 weeks for male routine appointments and an average default (did not attend, DNA) rate of $21 \%$. The May $2004 \mathrm{BASHH} / \mathrm{HPA}$ summary of waiting times for patients attending our clinic shows that, overall, only $22 \%$ of patients attending were given a routine appointment within 48 hours. $^{4}$

After 12 months of operating the closed appointment system, our DNA rate had fallen to $9.9 \%$ but the waiting times survey in May 2005 showed only 33\% achieved 48 hour access. Complaints from patients and primary care suggested that many people had difficulty getting through to book an appointment. This unsatisfactory situation led to an internal review to assess efficiency and capacity in the unit. It was decided to attempt to estimate the true demand on the closed appointment service.

The aim of the exercise is to establish the unmet need and demand for appointments in a GUM clinic and use this information to plan future services within the city.

\section{METHODS}

As part of a service improvement initiative, a multiprofessional group of nursing, medical, reception, and managerial staff wished to establish a method of assessing unmet need for a large inner city GUM department. An attempt to log and respond to every telephone call to the booking service was proposed, at two points in the year to allow for fluctuations in demand caused by the many higher and further education colleges served by the GUM department. The first survey, carried out in the summer, was seen as a pilot of the process in a relatively quiet month for student attendees. Ethics approval was not sought as this was an audit of current practice and the only new intervention was extra facility to answer the telephone. Five extra reception staff were trained in the clinic booking protocols and database. All reception staff on telephone booking duty were instructed in the routine set of questions and recorded the answers on a proforma (see appendix). Questions included caller's sex,

Abbreviations: DNA, did not attend; GUM, genitourinary medicine; HA, health authority; hcp, healthcare professional; STI, sexually transmitted infections 
Table 1 Route and reason for requesting an appointment

\begin{tabular}{|c|c|c|c|c|c|c|}
\hline & \multicolumn{6}{|c|}{ Reasons for requesting an appointment } \\
\hline & $\begin{array}{l}\text { Contact } \\
\text { slip }\end{array}$ & GP & hcp & $\begin{array}{l}\text { Sexual } \\
\text { partner }\end{array}$ & Self & Unknown \\
\hline $\begin{array}{l}\text { Telephone call } \\
\text { Walk-in } \\
\text { Written referral }\end{array}$ & $\begin{array}{l}9 \\
3\end{array}$ & $\begin{array}{l}49 \\
7 \\
22\end{array}$ & $\begin{array}{l}4 \\
4\end{array}$ & 18 & $\begin{array}{l}398 \\
109\end{array}$ & 13 \\
\hline
\end{tabular}

$G P$, general practice referral; $h c p$, other healthcare professional referral.

age, postcode of residence, and type of appointment needed, if the patients had any symptoms, how many times they had rung before. A cascade system of telephone extensions was established, with calls transferred automatically down a chain of five lines and the telephones were answered as they rang. All referrals received from other healthcare providers and external agencies were also recorded along with requests in person for appointments via reception.

Appointments booked via this standard booking service, plus a number of new appointments allotted by health advisers to patients after telephone triage made up the total of general appointments available. When all standard appointments were allocated, callers were advised of their options to ring again, speak to a health adviser for triage or advice, or seek alternative providers. Responses and call logs were collected and analysed in Excel.

Duplicate telephone calls were excluded based on caller postcodes and date of birth.

\section{RESULTS}

The exercise ran for the first 5 working days in July 2005.

Of a total of 585 telephone calls, 491(84\%) requested a new appointment. Calls were split almost equally between male and female (254 male, 232 female, five not recorded). The age distribution of callers was consistent with our usual clinic profile with the peak demand from callers aged 25-34 years. In all, $81 \%$ of callers gave local postcodes of residence; $45 \%$ of callers ( $40 \%$ female, $52 \%$ males) declared they had symptoms; $78 \%$ of people requesting a new appointment called once, $14 \%$ called twice, $4 \%$ called three times, and $4 \%$ of calls could not be classified.

\section{New appointment requests}

Telephone calls from the public for appointments made up $77 \%$ of all requests for appointments, with only $12 \%$ referrals originating from primary care or other healthcare providers. A total of 119 people ( 64 male, 55 female) attended reception to request an appointment in person, as self referrals, on partner advice or as referrals. These walk-ins made up 19\% of all requests. (table 1) In addition, there were 26 written or faxed referrals from other healthcare services.

\section{Estimated demand}

Assuming all patients requesting appointments would attend within 48 hours of expressing a need to be seen, an estimate of 636 (325 male, 311 female) new appointments in 1 week would be needed to meet this demand.

\section{Actual appointments and current maximum capacity} In the week under study, the available new GUM appointments were calculated from available slots within the medical and nursing lists. Nurse led male asymptomatic clinics and 38 medical clinics for males and females were scheduled, with $30 \%$ of appointments allocated for HIV patients. Thus, 112 male and 97 female GUM appointments were offered; 28 of these had already been allocated to

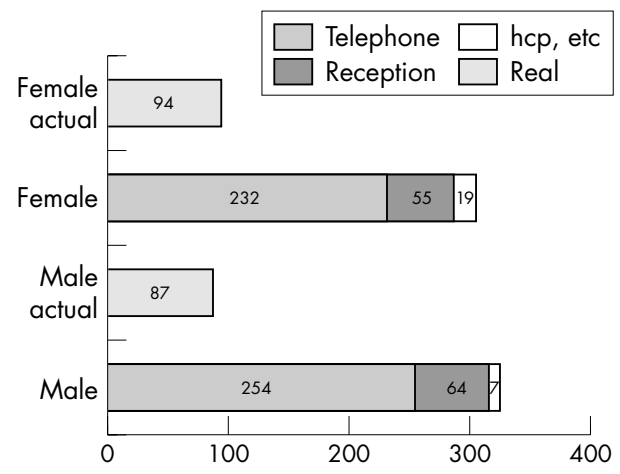

Figure 1 Available appointments and requested appointments by sex and source of referral: telephone, self referral telephone booking; reception, patients walking in as self referrals or carrying referrals; hcp, etc, referrals for other healthcare professionals, police, and other medical specialties; real, available appointments.

written referrals or triage from the previous week, leaving 181 available to be booked in the week.

The theoretical maximum capacity of the clinic to offer appointments in this week, based on a 44 week year worked by all staff would be 97 male and 98 female general appointments. Thus, in that week, the clinic was running at $103 \%$ capacity (fig 1 ).

For this week the clinic was unable to make appointments for 455 people ( 238 male, 217 female) or $72 \%$ of requests. To address this shortfall in the current clinic configuration would require an extra 96 clinic sessions to be manned, an increase of $253 \%$. If a backlog exercise was launched with purely new patient attendances and assuming 12 patients per 3.5 hour clinical session without follow up or HIV appointments, we would have to double the medical clinics offered per week

\section{DISCUSSION}

This exercise gave the first estimate of the unmet demand by telephone callers for access to a sexual health service in Britain. By overmanning the telephone bureau, a huge mismatch between attempts to book an appointment and actual provision was uncovered. Other studies of access issues in GUM clinics have interviewed those who succeeded in obtaining an appointment, ${ }^{56}$ used mock patients, ${ }^{7}$ asked lead clinicians supplying the service to comment on access, ${ }^{2}$ or considered the views of those accessing other sexual health services. ${ }^{8}$

In our clinic, we reserve a proportion of new appointments for symptomatic patients. This may offer some scope to allow for emergency patients, but the reliance on presentation of symptoms as a means of triage is misleading and inequitable. ${ }^{9}$ In a clinic population where the articulate and well informed patient may gain priority over those truly in need and where women in particular have a large burden of 
asymptomatic disease, triage at booking presentation is fraught with clinical risk. In a survey of service users in London clinics McClean $e t$ al $^{5}$ found that half the patients had delayed any attempt at access for 2 weeks on average from symptom development in the hope that the problem would go away. Women asked about preferences for access in another London based survey of family planning and GUM clinic service users would not report symptoms regarded as minor or ascribe them to other possible causes unless they thought they were unusual or were frightened by them. ${ }^{6}$

A rising demand at a population level has been demonstrated in a comparison of the two British National Surveys of Sexual Attitudes and Lifestyles (Natsal) in 1990 and 2000. ${ }^{10}{ }^{11}$ The number of those reporting use of GUM services has risen to $7.6 \%$ from $4.3 \%$ in men and from $3.3 \%$ to $6.6 \%$ in women, with highest increases seen outside Greater London, in women and in homosexual men. Clinics appear to be effective at attracting those at greatest need of their treatment, health education, and prevention services with over $60 \%$ attenders reporting risk factors for STI compared with $14 \%$ non-attending populations. First time attenders to GUM clinics valued the competence and specialist nature of GUM clinics and the confidentiality offered. ${ }^{8}$

The pressure on all clinics to use resources to the full has been growing for the past decade. Surveys indicate that GUM services have more than doubled their capacity through extensive modernisation, role modification, and reduction in follow up visits, ${ }^{1}$ with a $10 \%$ increase in resources, which only became available from 2003. Many clinics abandoned walkin services, and introduced various models of appointment systems. ${ }^{23}$ The closed appointment system, where booking is only available a fixed period ahead, has become unpopular in British primary care since it discriminates against all those unable to telephone within strict time limits or disinclined to persist to obtain an appointment. It does give the impression that a 48 hour target is being met, but we have shown that is true for only a small fraction of those attempting to call. Our estimates do not include those with the need to make an appointment who have no knowledge of how to contact the service or who cannot ring in office hours, perhaps because they are at school or work. The college population in our city was depleted at the time of the survey, and we might expect an even greater disparity between supply and demand in term time. We also have no knowledge of the numbers of service users attending other providers such as primary care or family planning services where some STI screening and/or treatment may be available. Sexual health advertising campaigns planned for England in early 2006 are expected to produce an additional increase in demand of $15 \%$ for appointments. ${ }^{1}$

GUM clinics remain the major provider of diagnostic and treatment services in the United Kingdom. Modelling the impact of limited access to GUM services on the control of gonorrhoea $^{12}$ in the United Kingdom indicates that immediate increases of $30-50 \%$ are required for cost effective management; a virtuous circle develops to maintain low population prevalence. Conversely, gradual or smaller increases would have limited effect and would cost more in the long term with additional transmissions, HIV transmission enhancement, and complication management-a recipe for a vicious circle.

In this centre, the demand for outpatient HIV services had risen by sevenfold from 1990 to 2005. Medical clinic time for HIV monitoring and emergency care was excluded from the calculations of capacity. GUM services are often the major provider of HIV medical outpatient services, and the $20 \%$ year on year increase in HIV diagnoses in United Kingdom ${ }^{13}$ has added further pressure to divert GUM resources to outpatient care of HIV in many centres.

\section{CONCLUSIONS}

STI diagnostic and treatment services in the United Kingdom are under huge pressure of demand from a public willing to attend for screening and resolution of symptoms. Some of these functions may be augmented by community providers in time, given the rollout of a national chlamydia screening programme and the movement to develop community services in preference to hospitals. ${ }^{14}$ The current urgent need to attempt to address the capacity/demand mismatch cannot wait for training and development of additional or alternative providers if we are to control the burgeoning epidemic of STIs within our population.

\section{ACKNOWLEDGEMENTS}

Our thanks go to the staff of the Department of Genitourinary Medicine clinic, especially the members of the GUM multidisciplinary modernisation group (access): Donna Wilson, Julia Bramble, and Hannah Bridge; to Vince Heslop for help organising and training the staff; to all reception staff; to Drs Eric Monteiro, Amy Evans, and Janet Wilson for helpful discussions; and to Craig Brigg and the Clinical Management Team at Leeds Teaching Hospitals Trust for financial and managerial support for the exercise.

\section{CONTRIBUTORS}

All authors contributed to initial idea, proforma development, and manuscript editing; YT trained and supervised the staff performing the audit; YT and HC analysed the data; JC commented on the initial data and wrote the draft for submission; JC is guarantor of the paper.

\section{Authors' affiliations}

J Clarke, H Christodoulides, Y Taylor, Department of Genitourinary Medicine, Centre for Sexual Health, Leeds Teaching Hospitals NHS Trust, Leeds General Infirmary, Great George Street, Leeds LS1 3EX, UK

Conflict of interest: none declared.

\section{APPENDIX}

\section{COPY OF TELEPHONE CLINIC PROFORMA}

- Day of week: time.

- Referral point: reception-self by phone

- Reception-with GP letter

- Secretaries-hcp by phone

- Secretaries-hcp by letter

- Secretaries-doctor request

- HA-by letter

- HA-by phone

- Other.

- Reason for referral: appointment request

- Cancel appointment

- Cancel and rebook

- Results query

- Advice

- Appointment confirmation

- Directions

- Other.

For appointment request or cancel and rebook

- Sex: male, female

- Appointment type: new

- Reason for referral:

- Follow up

- Nurse treatment

- HIV CNS 
- SDT

- $\mathrm{H} \# 2$

- Date of birth

- Postcode

- Symptomatic, asymptomatic

- Reason for appointment: routine check

- Partner advised

- Contact slip

- GP advice

- Other hcp advice

- Other

- Special: yes, no

- Appointment given: yes, no.

At this point either confirm appointment, advise to contact HA team, explain no appointments

Explain that we are auditing demand for the service and ask if they would mind answering a few questions about the service.

- Would you have a preferred time and day to be seen?

- How many times have you called today and received the engaged tone?

- Would you prefer us to have a call queuing system?

- On how many days in the last $X$ days have you unsuccessfully tried to get an appointment?

\section{REFERENCES}

1 BASHH GU Medicine Modernisation Group. Capacity building to reach 48hour access: making the case to PCTs published at www.bashh.org/.

2 Griffiths V, Ahmed-Jusuf-I, Cassell J, on behalf of AGUM. Understanding access to genitourinary medicine services. Int J STD AIDS 2004;15:587-9.

3 Robinson AJ, Rogstad K. Modernization in GUM/HIV services: what does it mean? Int J STD AIDS 2003;14:89-98.

4 Health Protection Agency. GUM waiting times audit. A national audit of access to genitourinary medicine clinics. May 2005 (www.hpa.org.uk/ infections/topics_az/hiv_and_sti/epidemiology/Report\%20_0505.pdf).

5 McClean HL, Reid M. Use of GUM services and information and views held by first time service users in a large UK city: implications for information provision Int J STD AIDS 1997; 8: 154-8.

6 Dixon-Woods M, Stokes T, Young B, et al. Choosing and using services for sexual health: a qualitative study of women's views Sex Transm Infect 2001;77:335-9.

7 Foley E, Patel R, Green N, et al. Access to genitourinary medicine clinics in the United Kingdom. Sex Transm Infect 2001;77:12-14.

8 Cassell JA, Brook MG, Mercer $\mathrm{CH}$, et al. Treating sexually transmitted infections in primary care: a missed opportunity? Sex Transm Infect 2003;79:134-6.

9 Kinghorn GR. Patient access to GUM clinics Sex Transm Infect 2001;77:1-2.

10 Johnson AM, Wadsworth J, Wellings $K$, et al. Who goes to sexually transmitted disease clinics? Results from a national population survey. Genitourin Med 1996;72:197-202.

11 Fenton KA, Mercer CH, Johnson AM, et al. Reported sexually transmitted disease clinic attendance and sexually transmitted infections in Britain: prevalence, risk factors and proportionate population burden. $J$ Infect Dis 2005; 191(suppl 1):S127-38.

12 White PJ, Ward H, Cassell JA, et al. Vicious and virtuous circles in the dynamics of infectious disease and the provision of healthcare: gonorrhea in Britain as an example. J Infect Dis 2005;192:824-36.

13 Health Protection Agency. Survey of prevalent HIV infections diagnosed (SOPHID), May 2005. (www.hpa.org.uk/infections/topics_az/hiv_and_sti/ hiv/epidemiology/files/2004_SHA_Web_tables.pdf).

14 Department of Health. Choosing health, Public health white paper. London: HMSO, 2004

\section{1th European Forum on Quality Improvement in Health Care}

26-28 April 2006, Prague, Czech Republic

For further information please go to: www.quality.bmjpg.com

Book early to benefit from a discounted delegate rate 